\title{
LISTING OF DISSERTATIONS
}

This listing has been compiled from University Microfilms International, 300 N. Zeeb, Ann Arbor, MI 48109. Abstracts of dissertations are available on the Journal's web site at www.jibs.net. Graduate students and their supervisors should provide doctoral dissertation abstracts of interest to JIBS by mailing a diskette containing the electronic file to the Journal's Washington, D.C., USA office or by attaching an MS Word file to an e-mail message and sending to jibs@msb.edu.

Muhammed Khurrum Shahzad Bhutta, Global Supply Chains: An Integrated Location, Production Distribution and Investment Model for a Multinational Corporation Operating Under Varying Exchange Rates and Tariff Structures, The University of Texas at Arlington, 2001. Adviser: Faizul Huq

Soon-Gwon Choi, Knowledge Translation in the Internationalization of Firms, Uppsala Universitet (Sweden), 2001

Kush Haq, An Analysis of the Determinants of United States Direct Investment Abroad in the Manufacturing Sector, State University of New York at Buffalo, 2001. Adviser: Sharmistha Bagchi-Sen

Canfei He, Locational Choices and Export Decisions of Foreign Manufacturing Enterprises in China, Arizona State University, 2001. Adviser: Breandan O'Huallachain

Taejoo Kim, The Effects of Taxes on Foreign Direct Investment in the United States, Michigan State University, 2001. Adviser: Charles L. Ballard

Kaoru Nabeshima, What Drives Japanese FDI Decisions? A Firm-level Analysis, University of California-Davis, 2001. Adviser: Lee Branstetter

Susan Denise Peters, Culture and the Timing of Foreign Direct Investment: The Case of Poland, the Czech Republic and Hungary, Saint Louis University, 2001. Adviser: Seung H. Kim

Karen Elizabeth Ruckman, Essays on International Business Strategy of Non-Traditional Goods, The University of British Columbia (Canada), 2001. Advisers: Barbara Spencer, Keith Head

Deepak Sethi, Liability of Foreignness to Competitive Advantage: An Empirical Study of Multinational Enterprise Strategies for Negotiating the International Business Environment, The University of Texas at Dallas, 2001. Advisers: Stephen E. Guisinger; David L. Ford Jr.

Amitabh Singh, Foreign Direct Investment from Developing Countries: A Case Study of India, The University of North Carolina at Chapel Hill, 2001. Adviser: Helen Tauchen

Douglas E. Thomas, Who Goes Abroad? International Diversification by Emerging Market Firms into Developed Markets, Texas A\&M University, 2001. Advisers: Lorraine Eden, Michael Hitt 